\title{
Effect of Benzoylsalicylic Acid on IKK-Beta Kinase and NF-KB Pathway in Murine Macrophage raw 264.7 Cells
}

Samuel Kamatham ( $\nabla$ samuelbioc@gmail.com )

University of Hyderabad

Naresh Babu V. Sepuri

University of Hyderabad

Naresh Kumar

University of Hyderabad

\section{Research Article}

Keywords: Benzoylsalicylic acid, Acetylsalicylic acid, Salicylic acid, Cyclooxygenase, ІкB kinase- $\beta$, ІкB kinase- $a$, Nuclear factor $\mathrm{kB}$

Posted Date: September 29th, 2021

DOI: https://doi.org/10.21203/rs.3.rs-941317/v1

License: (a) (1) This work is licensed under a Creative Commons Attribution 4.0 International License. Read Full License 


\section{Abstract}

The transcription factor NF-KB regulates a large array of genes of immune and inflammatory responses. Deregulated NF-KB signalling is implicated in the pathogenesis and broad spectrum of human inflammatory disorders and malignancies. The mechanism for NF-KB activation is the inducible degradation of IKB, triggered through its site-specific phosphorylation by a multi-subunit IKB kinase (IKK) complex. Aspirin (acetylsalicylic acid) a well-known anti-inflammatory agent that binds to ATP binding pocket of IKK $\beta$ and inhibits its kinase activity. However, several side effects of aspirin due to the inactivation of COX-1 limits the therapeutic usage of ASA. Here we have demonstrate the effect of a plant phenolic compound benzoylsalicylic acid (BzSA) isolated first time in plants a potent anti-viral compound inhibits Tobacco mosaic virus (TMV) and enhance the plant defense response (Samuel et all 2016\&2017) inhibit the IKK $\beta$ mediated NF-KB pathway higher than aspirin. Our In-vitro COX enzymatic assays with BzSA have shown less COX-1 and high COX-2 inhibition as compared to ASA. Western blotting analysis of Raw 264.7 cells that were pre-treated with BzSA down-regulated LPS stimulated pIKK- $\beta$, plKB, NFKBp65, TNF- $\alpha$, COX-1, COX-2, 5-LOX, IL-1 $\beta$, and IL-6 higher than ASA. Therefore, our observations suggested that the potencial therapeutic value of BzSA an upcoming new inhibitor of NF-KB pathway and the dual inhibitor of COX2/5-LOX without effecting the usefull COX-1. Hence useful as an antiinflammatory agent like ASA.

\subsection{Introduction}

Inflammation is a part of complex biological response of body tissues to harmful stimuli, such as pathogens, damaged cells, or irritants and also a critical component of tumour progression (Coussens and Werb, 2002; Grivennikov et al., 2010). Several researchers has been reported since several decades that the malignancies are initiated by infections, chronic irritation and inflammation (Coussens and Werb, 2002; Grivennikov et al., 2010; Kuper et al., 2000; Schoppmann et al., 2002). NF-kB is a well known protein complex that controls transcription of DNA, cytokine production and cell survival (Lawrence, 2009; Oeckinghaus and Ghosh, 2009). NF-KB is found in almost all animal cell types and involved in cellular responses to stimuli such as stress, cytokines, free radicals, heavy metals, ultraviolet irradiation,oxidized LDL and bacterial or viral antigens (Brasier, 2006; Gilmore, 1999, 2006; Perkins, 2007). In most cell types, $\mathrm{NF}-\mathrm{KB}-\mathrm{IKB}_{\mathrm{K}}$ inactive complex resides in the cytoplasm and its activation requires IKB kinase mediated phosphorylation of ІкB kinase and its ubiquitin mediated degradation. NF-KB plays a key role in regulating the immune responses to infection and acts as a critical components of immunoglobulins. Incorrect regulation of NF-KB leading to various cancers, inflammatory, cardiovascular, autoimmune diseases, septic shock, viral infection and improper immune development (Viatour et al., 2005). Bacterial Lipopolysaccharide (LPS) can induce NF-kB pathway (Zhang and Ghosh, 2000). The IKB kinase (IKK) is an enzyme complex and a part of the the upstream NF-KB signal transduction cascade such as IKK-a and IKK- $\beta$ involved in the cellular response to inflammation. The catalytic activities of IKK- $\alpha$ and IKK- $\beta$ make essential contributions to IKB-a phosphorylation, and dissociation of cytosolic IKB-NF-KB inactive complex and translocation of active phospho-NF-KB P65 to the nucleous (Israel, 2010; Zandi et al., 1997) 
and thus acts as a transcription factor for the induction of TNFa, COX-2, iNOS as well as cytokines like IL1, IL-2 and IL-6 (Aggarwal, 2006; Esposito and Cuzzocrea, 2009; Liu et al., 2013; Pahl, 1999). Thus, identification of new NF-KB inhibitors are the promising therapeutics to prevent inflammation and cancer diseases (Andres et al., 2013; Xu et al., 2011). Previously, it was reported that ASA and sodium salicylate inhibit the IKK- $\beta$ and therefore blocks the activation of NF-KB pathway (Yin et al., 1998). NF-KB is a hallmark of inflammatory responses and plays a fundamental role in inflammation and associated cancers (Pikarsky et al., 2004). Literature survey suggested that a number of chemical activators targets the genes of NF-KB pathway (Pahl, 1999). Chebulagic acid (CA) a natural plant compound shown the anti-inflammatory effects on LPS-stimulated RAW 264.7 macrophages through NF-KB inhibition and also MAP kinase phosphorylation (Reddy and Reddanna, 2009). NF-KB controls many physiological processes including inflammation, immunity, apoptosis and angiogenesis (Aggarwal, 2006; Hayden and Ghosh, 2008; Vallabhapurapu and Karin, 2009). Baicalein a natural compound suppressed TNF-a- induced NF-KB activation and its target gene products (Li et al., 2016).

Cyclooxygenases (COX-1 and COX-2) and lipoxygenases (5-LOX) are the key enzymes of arachidonic acid (AA) metabolism (Dannhardt and Kiefer, 2001; Greene et al., 2011). COX enzymes catalyses the conversion of AA to prostaglandins (PGs) and thromboxanes (Seibert et al., 1994). COX-1 constitutively expressed in mast cells and also different organs whereas, COX-2 localized primarily in inflammatory cells and tissues and the selective COX-2 inhibitors are exceedingly beneficial anti-inflammatory drugs (Seibert and Masferrer, 1994; Seibert et al., 1994). Literature suggested that offensive up-regulation of COX-2 and iNOS has been associated with pathophysiology of certain types of human cancers as well as inflammatory disorders (Surh et al., 2001). ASA is a widely used non-steroidal anti-inflammatory (NSAID) drug world wide (Alfonso et al., 2014; Wentz et al., 1976). The anti-thrombic and anti-ulcerogenic side effects of ASA largely due to the acetylation of Ser ${ }^{530}$ in COX-1 and Ser ${ }^{516}$ in COX-2 (Kalgutkar et al., 1998). Inhibition of COX-1 by ASA and other NSAIDs causes side effects (Brune and Patrignani, 2015). Recent studies have suggested that ASA works as a chemo preventive agent in several cancers (Goodman and Grossman, 2014). Besides COXs, ASA also acetylates several other bio-molecules and affects their function (Alfonso et al., 2014; Rainsford et al., 1983). Previous reports suggested that chemically synthesized ASA like molecules selectively inactivate COX-2 more effectively than ASA (Beauchamp et al., 2005; Kalgutkar et al., 1998; Kalgutkar et al., 2000). Rofecoxib and celecoxib are selective inhibitors of COX-2 whereas meloxicam inhibit COX-2 by different mechanism (Hawkey, 2001). Several reports suggested that the phytochemicals like curcumin, epigallocatechin gallate (EGCG), resveratrol inhibit COX-2 and are proven to be effective anti-inflammatory and anti-cancer agents (Surh et al., 2001).

To the best of my knowledge we isolated first time BzSA from the seed coats of Givotiarottleriformis and shown its role in plant systemic defense against TMV virus (S. Kamatham et al., 2016). The plant G.rottleriformisis tree species belongs to Euphorbiaceae family and are known have anti-rheumatism, anti-psoriasis and anti-dandruff medicinal properties. Phytochemical analysis of G.rottleriformis seed coats provides the evidences to the medicinal value of this plant as we identified important 
pharmaceutical molecules such as salicylic acid (SA), benzoic acid (BA), gallic acid (GA) and methylgallate (MG) (Kamatham et al., 2016; Samuel Kamatham, 2015). The purified GA and MG from seed coats of this plant exhibit anti-cancer potential against the proliferation of A431skin cancer cellline without effecting the normal HaCaTcellline (Samuel Kamatham, 2015).

The present study have shown the anti-inflammatory and anti-cancer potential of BzSA in RAW 264.7 cells. Structurally BzSA is a natural and ASA is a synthetic analogue of SA (Fig. 1). The effect of BzSA on COX-1 and COX-2 inhibition was studied and compared with ASA. This study shown the evedances of BzSA down-regulated IKK- $\beta$ and the down-stream NF-KB pathway higher as compare to ASA in a dosedependent manner.

\subsection{Materials And Methods}

\subsection{Cell lines and reagents}

RAW 264.7 cells were obtained from National Centre for Cell Science (NCCS), Pune, India. DMEM, Fetalbovine serum (FBS), Phosphate-buffered saline (PBS), Penicillin, Gentamycin and Streptomycinwas purchased from Gibco, Ltd, (BRL Life Technologies, Inc., Grand Island, NY). MTT [3-(4, 5-dimethylthiazol2yl)-2, 5-diphenyL tetrazolium bromide] and Dimethylsulpoxide (DMSO), Lipopolysaccharide (LPS),Poly-Llysine, Glutaraldehyde, Proteinase inhibitor K, Propidium iodide (PI), Phenylmethylsulfonylfluoride (PMSF), Leupeptin, Aprotinin, Pepstatin A, Trypsin, Tween-20, Triton X-100, TMPD (N,N,N,N'-tetramethyl pphenylenediamine) purchased from Sigma (St. Louis, USA). All the antibodies, chemicals and reagents used in this study were purchased from Cell signalling (USA), Santacruz (USA) and Abcam (USA), Merck andSigma (USA).

\subsection{Cell culture}

RAW 264.7 murine macrophase cells were cultured as a monolayer in petridish and supplemented with DMEM medium containing $10 \%$ heat inactivated FBS, $100 \mathrm{IU} / \mathrm{ml}$ penicillin, $100 \mu \mathrm{g} / \mathrm{ml}$ streptomycin, $2 \mathrm{mM}$ L-glutamine and maintained in a humidified atmosphere with 5\% CO2 at 37区C. The cells were subcultured alternative days and the exponentially growing cells were used for the treatments.

\subsection{MTT assay}

RAW 264.7 cells ( $5 \times 10^{3}$ cells per well) were seeded in 96 well plates and incubated in the presence or absence of BzSA or ASA $(0.001,0.01,0.1,1.0$, and $10 \mathrm{mM})$ for $24 \mathrm{~h}$ and $48 \mathrm{~h}$. In a final volume of $100 \mu \mathrm{l}$, $20 \mu \mathrm{l}$ of MTT $\left(5 \mathrm{mg} / \mathrm{ml}\right.$ in PBS) was added to each well and incubated for an additional $3 \mathrm{~h}$ at $37^{\circ} \mathrm{C}$. Then the culture medium was removed from the wells and added $200 \mu \mathrm{l}$ of DMSO followed by dissolved the purple blue formazan crystals. The optical color density was quantified at $570 \mathrm{~nm}$ on ELISA multi-mode plate reader (SYNERGYMX, Biotech). All the experiments are repeated three times under the same conditions. 


\subsection{Preparation of whole cell extract and Western bloting analysis}

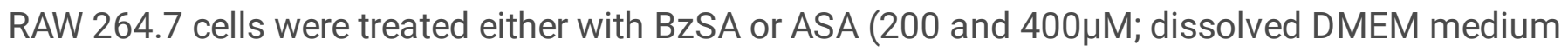
containing $0.01 \%$ DMSO) for $24 \mathrm{~h}$ followed by stimulated with $25 \mathrm{ng} / \mathrm{mL}$ LPS for $2 \mathrm{~h}$. DMSO and LPS treated cells were maintained as positive and negative controls. After the pre-treatment, the cells were washed with 1X PBS and re-suspended in a RIPA lysis and extraction buffer containing 1X protease inhibitor cocktail followed by incubation for $30 \mathrm{~min}$ at $4^{\circ} \mathrm{C}$ with a frequent vortexing. Then the lysate was centrifuged at $12,000 \mathrm{rpm}$ for $20 \mathrm{~min}$ and collected the supernatant and the total protein concentration was estimated by Bradford protein assay (Bradford, 1976) and stored at $-20^{\circ} \mathrm{C}$ for further use. The protein samples $(20 \mu \mathrm{g})$ was resolved on $12 \%$ SDS-PAGE and then transferred onto nitrocellulose (NC) membrane. Then the NC membrane were incubatedin $5 \%(\mathrm{w} / \mathrm{v})$ non-fat dry milk powder at RT for $1 \mathrm{~h}$ to block nonspecific sites and incubated with primary antibody of interest ( both phospho and total IKK-a, IKK- $\beta$, ІкBa, IKBa, NF-KBp65 and TNF-a, COX-1, COX-2, iNOS and IL1 $\beta$ ) overnight at $4^{\circ} \mathrm{C}$ under shaking followed by washing with TBST for 3 times 10 min each. The NC membrane were then incubated with respective secondary antibody conjugated with HRP for $1 \mathrm{~h}$ at RT followed by washing with TBST for 3 times 10 min each. Finally, the blot were developed by adding HRP substrate followed by recorded using gel documentation system (Bio-rad).

\subsection{Isolation of COX-1 enzyme}

COX-1 enzyme was isolated from Ram seminal vesicles according to Hemleret al; 1976 (Hemler and Lands, 1976), with a slight modifications. In brief, Ram seminal vesicles were homogenized with a grinder in Tris- $\mathrm{HCl}(\mathrm{pH} \mathrm{8.0)}$ buffer for $1 \mathrm{~min}$ and then the homogenate was filtered through cheese cloth and centrifuged at $13,000 \mathrm{~g}$ at $4^{\circ} \mathrm{C}$ for $30 \mathrm{~min}$. Finally, $0.01 \%$ sodium azide was added and stored in small aliquots at $-80^{\circ} \mathrm{C}$ and used as a COX-1 enzyme.

\subsection{Isolation of COX-2 enzyme}

The enzyme COX-2 was isolated according to Reddy et al; 2000 (Reddy et al., 2000) with slight modifications. In brief, the human recombinant COX-2 enzyme was expressed in Sf-9 cells, harvested the cells and sonicated for $3 \mathrm{~min}$ in $50 \mathrm{mM}$ Tris-HCl buffer $(\mathrm{pH} 7.2)$ followed by centrifuged at $100,000 \mathrm{~g}$ at $4^{\circ} \mathrm{C}$ for 80 min using ultracentrifuge (Hitachi, Himac CP-100a). Then the cell pellet was resuspended in $2.5 \mathrm{mM}$ Tris- $\mathrm{HCl}$ buffer ( $\mathrm{pH} 7.2), 0.8 \%$ Tween- $20,1 \mathrm{mM}$ phenol, and $0.5 \%$ glycerol, and stored in small aliquots at $-80^{\circ} \mathrm{C}$ and used as a COX-2 enzyme.

\subsection{COX-1 and COX-2 enzyme activity}

The enzymatic activities of both COX-1 and COX-2 were measured according to Copeland et al; 1994 (Copeland et al., 1994) with slight modifications based on the a chromogenic assay and oxidation of $\mathrm{N}, \mathrm{N}, \mathrm{N}$ ", N"-tetramethyl-p-phenylene diamine (TMPD) during the reduction of $\mathrm{PGG}_{2}$ to $\mathrm{PGH}_{2}$. In brief, the assay mixture contained Tris-HCl buffer $(100 \mathrm{mM}, \mathrm{pH} 8.0)$, hematin $(15 \mu \mathrm{M})$, EDTA $(3 \mu \mathrm{M})$, enzyme (COX-1 or COX-2) and the test compounds (BzSA or ASA). Then the assay mixture was pre-incubated for $15 \mathrm{~min}$ 
at $25^{\circ} \mathrm{C}$ and the reaction was initiated by addition of arachidonic acid (AA) and TMPD in a final volume of $1 \mathrm{ml}$. The enzyme activity was measured after $1 \mathrm{~min}$ by estimated initial TMPD oxidation by monitoring absorbance at $603 \mathrm{~nm}$. A low rate of non-enzymatic TMPD oxidation was observed in the absence of COX-1 or COX-2 enzymes and are treated as control reaction and were normalised from the test experimental values while calculating the percentage of inhibition. Each experiment were repeated three times under the same conditions.

\subsection{5-LOX assay}

Similarly, we purified the 5-LOX enzyme from potato tubers and assayed according to Reddanna et al,1990 (Reddanna et al., 1990). Enzyme activity was measured using polarographic method with a Clark's oxygen electrode on Strathkelvin Instruments, model 782, RC-300. The typical reaction mixture contained $50-100 \mu \mathrm{l}$ of enzyme and $10 \mu \mathrm{l}$ of the substrate $(133 \mu \mathrm{M}$ of $A A)$ in a total volume of $3 \mathrm{ml}$ with $100 \mathrm{mM}$ phosphate buffer $\mathrm{pH}$ 6.3. The rate of decrease in oxygen concentration was taken as a measure of enzyme activity. Stock solutions of BzSA and ASA were prepared freshly in DMSO before use. Various concentrations of BzSA and ASA were prepared and the LOX reaction was initiated by the addition of substrate. The reaction was allowed to proceed at $25^{\circ} \mathrm{C}$ and the maximum slope generated was taken for calculating the enzyme activity. The percentageof inhibition was calculated by comparison of LOX activity in the presence or absence of inhibitor. The concentration of the test compound causing $50 \%$ inhibition $\left(\mathrm{IC}_{50}\right)$ was calculated from the concentration-inhibition response curve. The experiment were repeated for three times under the same conditions.

\subsection{Results}

\subsubsection{Cytotoxicity assay}

The cytotoxic effect of BzSA was determined and compared with ASA in Raw 264.7 cells (Fig. 2a-f). Raw 264.7 cell that were pre-treated with BzSA have shown its cytotoxic effect with an $\mathrm{IC}_{50}$ value of $3.0 \mathrm{mM}$ at $24 \mathrm{~h}$ and $48 \mathrm{~h}$ (Fig. 2a-c). In contrast, ASA shown its cytotoxic affect with an $\mathrm{IC}_{50}$ value of $5.0 \mathrm{mM}$ at $24 \mathrm{~h}$ and $48 \mathrm{~h}$ respectively (Fig. $2 \mathrm{~d}$-f).

\subsubsection{Effect of BzSA on COX-1/COX-2 and 5-LOX enzyme activity}

In order to determine the effect of BzSA on COX-1, COX-2 and 5-LOX enzyme activity we perform in vitro enzymatic assays. Interestingly, $4.2 \mathrm{mM} \mathrm{BzSA}$ showed $10 \%$ COX-1 and 35\% COX-2 inhibition (Table 1). Whereas, 4.2 mM ASA shown 95\% COX-1 and 11\% COX-2 enzyme (Table 1). However, BzSA and ASA have no inhibition effect on 5-LOX enzyme activity even at increasing concentrations (Table 1). 
Table 1

COX-1, COX-2 and 5-LOX enzyme assays with BzSA and ASA.

\begin{tabular}{|lllll|}
\hline & Treatment & \%COX-1 Inhibition & \%COX-2 Inhibition & \%5-LOX inhibition \\
\hline BZSA 4.2mM & $10 \%$ & $35 \%$ & 0.0 \\
\hline ASA $4.2 \mathrm{mM}$ & $95 \%$ & $11 \%$ & 0.0 \\
\hline 3.1 .3 Effect of BzSA and ASA on COX-1 expression
\end{tabular}

To examine the effect of BzSA on COX-1 expression we performed western bloting in RAW 264.7 cells that were stimulated with LPS. Previous reports has been suggested that COX-1 required to maintaine the body physiology and constitutively expressed in the gastrointestinal tract and many other tissues in the body including lung, kidney, stomach, platelets and monocytes etc. Interestingly, in our results pretreatment of BzSA and ASA does not effect the COX-1 expression upon LPS stimulation (Fig. 3).

\subsubsection{COX-2}

COX-2/5-LOX dual inhibitors are the promising pharmaceutical value for the development of potent drugs to cancer and various inflammatory diseases. RAW 264.7 cells that were pretreated with BzSA downredulated LPS stimulated COX-2 completely at $200 \mu \mathrm{M}$ (Fig. 3). Whereas cells that were pretreated with ASA down-regulated LPS stimulated COX-2 less than BSA in a dose dedendent manner (Fig. 3). These results highlite BzSA is a potant COX-2 inhibitor than ASA.

\subsubsection{5-LOX}

5-lipoxygenase (5-LOX) pathway is the major source of potent proinflammatory leukotrienes (LTs) issued from the metabolism of arachidonic acid (AA), and the best known for their roles in the pathogenesis of asthma. Dual COX-2/5-LOX inhibitors are promising drugs to treat inflammatory diseases. In our results, RAW 264.7 cells that were pretreated with $200 \mu \mathrm{M}$ BzSA down-regulated the expression of 5-LOX enzyme (Fig. 3). Whereas, RAW 264.7 cells that were pretreated with ASA reduced 5-LOX expression low as compared to BzSA (Fig. 3). These results suggest that BzSA is a potant 5-LOX inhibitor.

\subsubsection{Inhibition of IKK complex by BzSA}

The activation of catalytic kinase subunits of IKK kinase complex (IKKa and IKK $\beta$ ) is a regulatory step in two signalling pathways known as classical (canonical) pathway and the alternative (non-canonical) pathway, leading to the activation of NF-KB. The IKK mediated phosphorylation of IKB and proteosomal degradation are leading to the activation of NF-KB dimers, nuclear translocation and induction of target gene expression. Here we have shown the effect of BzSA on catalytic kinase subunits of IKK kinase complex (IKKa and IKK $\beta$ ) in RAW 264.7 cells in a dose responsive manner.

\subsubsection{IKK- $\alpha / \beta$ inhibition by BzSA}

In order to determine the effect of BzSA on NF-KB pathway and its regulatory IKK- $\mathrm{a} / \beta$ complex, we examine the effect of BzSA and ASA on LPS stimulated IKK- $\alpha$ / $\beta$ in RAW 264.7 cells. Interestingly, BzSA 
down-regulated LPS stimulated phospho IKK- $\alpha / \beta$ higher than ASA in a dose responsive manner (Fig. 4). However, The total IKKa and IKK- $\beta$ levels were remains same in BzSA, ASA and the controls (Fig. 4).

\subsubsection{IKB- $\mathrm{a}$}

The activation of NF-KB required phosphorylation and ubiquitination of phospho-IKB-a an inhibitor of NFKB by IKK- $\alpha /$ IKK- $\beta$ kinases. Western blotting analysis of IKB- $\alpha$ revelled that BzSA pre-treatment reduced LPS stimulated IKB-a completely as compared to ASA treatment (Fig. 4) and the total IKB-a levels were increased in BzSA pre-treatment over ASA (Fig. 4).

\subsubsection{NF-KB}

In order to determine the effect of BzSA on NF-KB activation, RAW 264.7 cells were pre-treated with BzSA and assess the inhibition of LPS stimulated p-NF-kBp65. Interestingly, down-regulation of p-NF-kB-p65 levels in BzSA pre-treated cells were reduced in a dose dependent manner upon LPS stimulation (Fig. 4). Whereas, in ASA pre-treated cells there was no much reduction of LPS stimulated p- NF-KB-p65 levels were noticed as compared to BzSA (Fig. 4).

\subsubsection{BzSA inhibits NF-KB- and its responsive gene expression in RAW 264.7 cells}

Nuclear translocation of p-NF-KBp65 triggers the expression of inflammatory mediators such as COX-1, COX-2, 5-LOX, TNF-a, iNOS and cytokines such as IL-1 $\beta$ and IL-6, whose expression play an important roles in immune, stress, apoptosis, cell proliferation, cell differentiation and development. Here pretreatment of BzSA down-regulated the expression of LPS stimulated inflammation mediators and cytokines in RAW 264.7 cells.

\subsubsection{TNF-a}

TNF- $a$ is an inflammation responsive marker protein and TNF- $a$ antagonists may be effective in treating various inflammatory disorders. Inhibition of TNF-a proved to be an effective therapy for patients with rheumatoid arthritis and other forms of inflammatory disease including psoriasis, psoriatic arthritis, ankylospondylitis and inflammatory bowel disease. A moderate reduction of reduction of TNF-a in BzSA and ASA pretreated RAW 264.7 cells were noticed (Fig. 5).

\subsection{2 iNOS}

Inducible nitric oxide synthase (iNOS) is one of the three key enzymes that generate nitric oxide (NO) from the amino acid arginine. iNOS-derived NO is a free radical, whose predominant function is that of a messenger through cGMP. iNOS-derived NO plays an important role in numerous physiological (e.g. blood pressure regulation, wound repair and host defence mechanisms) and pathophysiological (inflammation, infection, neoplastic diseases, liver cirrhosis, diabetes) conditions and associated with malignant disease. In particular, prevital effects such as malignant transformation, angiogenesis, and metastasis are modulated by iNOS. Interestingly, BzSA pre-treatment dow-regulated LPS stimulated iNOS in RAW 
264.7 cells in a dose wise (Fig. 5). Similarly, ASA pre-treatment were also down-regulated iNOS completely at $4 \mathrm{mM}$ (Fig. 5).

\subsubsection{BzSA inhibits IL-1 $\beta$ and IL-6}

Interleukin-1 $\beta$ (IL-1 $\beta$ ) and interleukin-6 (IL-6) are major inducers of hepatic inflammation and the acute phase response. Over expression of IL-6 has been implicated in the pathologyof a number of diseases including multiple myeloma, rheumatoid arthritis, castleman's disease, psoriasis, and post-menopausal osteoporosis. Hence selective antagonists of IL-6 may offer therapeutic benefits. Interestingly, BzSA

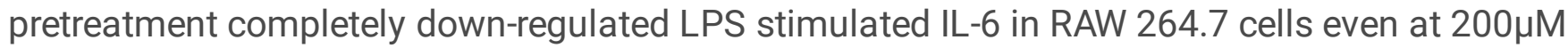
concentration (Fig. 5 ). Whereas ASA inhibit the expression of LPS stimulated IL- 6 in a dose dependent manner, however less effective compared to BzSA (Fig. 5). Similarly, our results shown that BzSA pretreated cells down-regulated IL-1 $\beta$ and IL-6in a dose dependent manner and found to be better response compared to ASA (Fig. 5).

\subsection{Discussion}

The present study have evaluated the anti-inflammatory properties of BzSA in RAW 264.7 cells as compared to a well known anti-inflammatory agent ASA. BzSA (Benzoylsalicylic acid) is first time purified from G.rottlerifirmis seed coats (Kamatham et al., 2016) where as ASA (Acetylsalicylic acid) a syntheric analogue of SA (Salicylic acid; Fig. 1). BzSA develops plants immunity and induced disease resistance in tobacco and Arabidopsis against TMV virus plants (Kamatham et al., 2016). Further more various chemically synthesized analogues of BzSA have shown a powerfull defence resistance against TMV virus even at low concentrations (Samuel et al, 2017). Inorder to deterimine the stability of BzSA We treated SA deficient Arabidopsis NahG plants with BzSA and check the defense response and surprisingly we were still able to see the defense response even in the absence of SA which indicates that BzSA is a stable molecule and does not undergo deacylation in the plants after treatment (Samuel et al 2016).

The cytotoxicity MTT assay results of RAW264.7 cells were shown that the $\mathrm{IC}_{50}$ value of BzSA slight higher than aspirin (Fig. 2). Aspirin indued a decrease in cell viability in a time and deose dependent manner (Bellosillo et al., 1998). Interestingly, BzSA have shown more COX-2 enzyme inhibition activity over ASA (Table 1). NSAIDs including aspirin, indomethacin and ibuprofen are non-selective inhibitors of COX-1 and COX-2, whereas, celecoxib and rofecoxib selectively inhibit COX-2 enzyme activity (Rao and Knaus, 2008). NSAIDs are potent anti-inflammatory and anti-cancer agents that acts through the inactivation of the COX enzymes, mostly COX-2 and thus directed the prostaglandins (PGs) synthesis at the site of inflammation (Rao and Knaus, 2008; Willoughby et al., 2000). BzSA have no effect on 5-LOX enzyme inhibition (Table 1). In view of the importance of dual COX-2/5-LOX, identification of specific inhibitors of COX-2/5-LOX proteins have therapeutic advantage (Fiorucci et al., 2001; Ranjbar et al., 2016). Interestingly, BzSA inhibits COX-2 and 5-LOX expression higher than aspirin (Fig. 3). COX-2 expression is highly restricted and selectively induced by pro-inflammatory cytokines at the site of inflammation and 
thus involved in the production of pro-inflammatory PGs (Crofford, 1997; Rao and Knaus, 2008; Seibert and Masferrer, 1994).

NF-KB induce 5- LOX enzyme expression during the inflammation process (Pahl, 1999). 5-LOX enzyme catalyzes AA metabolism in the leucocytes (Steinhilber, 1999). Leukotrienes (LTs) are the metabolic products of AA metabolism, which possess a potent pro-inflammatory activity and thus might be involved in cardiovascular diseases (de Gaetano et al., 2003). Decreased expression of 5-LOX gene enhanced cell death in breast cancer cells and therefore plays an essential role in reducing the tumor proliferation (Kumar et al., 2016). The 5-LOX enzyme inhibitor zileuton reduces inflammatory reaction in the ischemic brain damage through the activation of P13K/Akt signaling pathway (Tu et al., 2016). A report suggest that 7-subsituted coumarin derivatives are potential 5-LOX inhibitors (Srivastava et al., 2016).

Interestingly, the inhibition effect of BzSA on COX-1 enzymatic activity very low as compared to ASA (Table 1). However, BzSA and ASA have no effect at COX-1 expression even increasing concentrations (Fig. 3). One of the major disadvantage of ASA is inhibition of COX-1 and associated anti-thrombic and ulcerogenic side effects (Bianchi Porro and Pace, 1988; Undas et al., 2007). COX-1 expressed constitutively in almost all cell types in the human body and thus produced anti-inflammatory PGs which are important to maintain the homeostatic functions such as integrity of the gastric mucosa, platelet function, and renal blood flow (Allison et al., 1992). These results encouraging that the dentification of selective inhibitors of COX-2 with out effecting COX-1 are useful therapeutics.

In order to determine that BzSA is a potent inhibitor of NF-KB pathway we are pre-treated Raw 264.7 cells with BzSA and analysed the IKK- $\alpha / \mathrm{IKK}-\beta$ an essential up-stream signaling of NF-NF-KB. Surprisingly, BzSA down-regulated IKK- $\alpha / \beta$ expression higher than ASA (Fig. 4). NF-KB pathway is under the control of IKKkinase complex. IKKa/ $\beta$ phosphorylats IKB- $\alpha$ an inhibitor of NF-KB (Adli et al., 2010; Aggarwal, 2006; Karin and Delhase, 2000) and reduced phosphorylation of IKB and NF-KB pathway. ASA binds to IKK- $\beta$ and inhibit ATP binding and phosphorylation of ІкB (Aggarwal, 2006; Yin et al., 1998). In our results we also observed the similar action of BzSA on IKKa/ $\beta$ (Fig. 4). Phosphorylation of IKB-a by IKKa/ $\beta$ brings IKB-a$\mathrm{NF}-\mathrm{KB}$ inactive complex to active form and leading to the activation and localization of NF-KB in to nucleous (Aggarwal, 2006; Huang and Hung, 2013; Yamamoto and Gaynor, 2001; Yin et al., 1998). A dose wise IkBa inbibition and reduction in p-NF-KB p65 was observed in BzSA higher than ASA treatment and supported by previous observations (Fig. 4) (E.Britta-Mareen Traenckner et al., 1995; Vancurova and Vancura, 2012). NF-KB-DNA binding subunits are released and translocated into the nucleus thereby activates a wide range of inflammation responsive genes (Hayden and Ghosh, 2008; Rao and Knaus, 2008; Vallabhapurapu and Karin, 2009). Benzo[b]thiophen-2-yl-3-bromo-5-hydroxy-5H-furan-2-one (BTH) inhibited NF-KB and STAT3 phosphorylation (Andres et al., 2013). Isoorientin is a natural flavone reduced NF-KB in RAW 264.7 cells (Sumalatha et al., 2015). NF-KB recognized as a key player involved in many steps of cancer initiation and progression (Hoesel and Schmid, 2013; Karin, 2009).

In order to validate the effect of BzSA on NF-kB pathway we tested a series of NF-kB targeted inflammatory mediaters. BzSA suppressed COX-2 (Fig. 3 ). COX- 2 expression depends on NF-KB 
activation (Lim et al., 2001). Previosely it was reported that pro and anti-inflammatory nature of COX-2 (Poligone and Baldwin, 2001). The expression of inflammatory mediators such as TNF-a, COX-2, 5-LOX, iNOS and cytokines such as IL-1 $\beta$ and IL-6 require translocation of NF-KB from cytosol to nucleus (Rao and Knaus, 2008). TNF-a is a pleiotropic cytokine, which is a therapeutic target for inflammatory diseases therefore TNF- $a$ inhibitors are therapeutic advantages in inflammatory disorders and malignant diseases (Esposito and Cuzzocrea, 2009; Parameswaran and Patial, 2010). Previously, it was reported that ASA inhibits TNF-a gene expression in RAW 264.7 cells through the suppression of active NF-KB binding to the TNF-a promotor (Shackelford et al., 1997). No significant inhibition of TNF-a by BzSA and ASA noticed (Fig. 5). Literature suggested that induced expression of TNF-a activated by NF-KB in different cell lines (Ke et al., 2007; Parameswaran and Patial, 2010; Wajant et al., 2003). Similarly, the expression of iNOS depends on the nuclear localization of activated NF-KB. BzSA suppressed iNOS higher than ASA (Fig. 5). Previously, it was suggested that inducible nitric oxide synthase (iNOS) is activated by several immunological stimuli and the resultant accumulated nitric oxide cytotoxic to the cells. Furthermore, iNOS mutants exhibited reduced immune response to carrageenin and showed resistance to LPS induced mortality (Vig et al., 2004; Wei et al., 1995). Increased iNOS associated with malignant diseases, particularly malignant transformation, angiogenesis and metastasis (Lechner et al., 2005).

Interestingly, in our study we observed more suppression of IL-1 1 in BzSA treated cells as compared to ASA (Fig. 5). Interleukins are the cytokines important in the regulation of immune responses, inflammatory reactions and hematopoiesis. Over activation of inmmune system causes several inflammatory disorders. Anti-inflammatory agents including ASA, anti-cytokine therapies, small molecules and many drugs under clenical trails. IL-1 $\beta$ and IL- 6 are the the pro-inflammatory cytokines responds to inflammation. IL-1 $\beta$ induces IL-6 in peripheral blood monocytes (Tosato and Jones, 1990). Proinflammatory cytokines such as TNF-a, IL-1 $\beta$ and vascular growth factor (VEGF) plays a central role ininflammation (Dinarello, 2010). In our results we also noticed remarkable reduction in IL- 6 by BzSA in a dose dependent manner over ASA (Fig. 5). Previously reports demonstrated that IL-1 $\beta$ and TNF-a induce IL- 6 and most of the biological activities associated with IL-1 and IL-6 (Tosato and Jones, 1990).

\section{Conclusions}

Our findings highlighte the anti-inflammatory and anti-cancer therapeutic proterties of BzSA in RAW 264.7 cells. Interestingly, BzSA exhibited more COX-2 inhibition activity and low COX-1 inhibition activity over ASA. BzSA suppressed NF-KB pathway and the mechanism involves the inhibition of up-stream IKKcomplex is similar to ASA (Fig. 6). Hence we suggested that the BzSA is a potencial anti-inflammatory and anti-caner agent like aspirin.

\section{Abbreviations}

BzSA, benzoylsalicylic acid; SA, salicylic acid; ASA, acetylsalicylic acid; COX, cyclo-oxygenase; 5-LOX, 5lipooxygenase; NSAIDs, non-steroidal anti-inflammatory drugs; PG, prostaglandin, NF-KB, nuclear factor 
KB; IKB, inhibitor of NF-kB; IKKa, IkB kinase $\alpha$; IKK $\beta$, IkB kinase $\beta$; IL-1 $\beta$, interleukin-1 $\beta$; interleukin-6 iNOS, inducible nitricoxide synthase.

\section{Declarations}

\section{Conflict of interest Statement:}

We wish to confirm that there is no conflicts of interest associated with this publication and no significant financial support for this work that could have influenced its outcome.

\section{ACKNOWLEDGEMENTS}

Dr. KS gratefully acknowledges the Science and EngineeringResearch Board (SERB), India for the grant received under Fast Track Young Scientists Scheme. KS gratefully acknowledges Prof. Pallu Reddanna, Department of Animal Sciences, School of Life Sciences, University of Hyderabad for allowing me to use needful lab facilities. Finally we acknowledge the facilities at the School of Life Sciences, University of Hyderabad established with the support of UGC-SAP-CAS, DST-FIST and DBT-CREBB.

\section{References}

1. Adli, M., Merkhofer, E., Cogswell, P. \& Baldwin, A. S. IKKalpha and IKKbeta each function to regulate NF-kappaB activation in the TNF-induced/canonical pathway. PloS one, 5, (2010). e9428

2. Aggarwal, P. T. A. 2006. NF-kB transcription factor: a key player in the generation of immune response.CURRENT SCIENCEVOL. 90.

3. Alfonso, L., Ai, G., Spitale, R. C. \& Bhat, G. J. Molecular targets of aspirin and cancer prevention. Br J Cancer, 111, 61-67 (2014).

4. Allison, M. C., Howatson, A. G., Torrance, C. J., Lee, F. D. \& Russell, R. I. Gastrointestinal damage associated with the use of nonsteroidal antiinflammatory drugs. N Engl J Med, 327, 749-754 (1992).

5. Andres, R. M., Montesinos, M. C., Navalon, P., Paya, M. \& Terencio, M. C. NF-kappaB and STAT3 inhibition as a therapeutic strategy in psoriasis: in vitro and in vivo effects of BTH. J Invest Dermatol, 133, 2362-2371 (2013).

6. Beauchamp, G. K. et al. Phytochemistry: ibuprofen-like activity in extra-virgin olive oil. Nature, 437, 45-46 (2005).

7. Bellosillo, B. et al. Aspirin and salicylate induce apoptosis and activation of caspases in B-cell chronic lymphocytic leukemia cells., 92, 1406-1414 (1998).

8. Bianchi Porro, G. \& Pace, F. Ulcerogenic drugs and upper gastrointestinal bleeding. Bailliere's clinical gastroenterology, 2, 309-327 (1988).

9. Bradford, M. M. A rapid and sensitive method for the quantitation of microgram quantities of protein utilizing the principle of protein-dye binding. Anal Biochem, 72, 248-254 (1976). 
10. Brasier, A. R. The NF-kappaB regulatory network. Cardiovasc Toxicol, 6, 111-130 (2006).

11. Brune, K. \& Patrignani, P. New insights into the use of currently available non-steroidal antiinflammatory drugs. J Pain Res, 8, 105-118 (2015).

12. Copeland, R. A. et al. Mechanism of selective inhibition of the inducible isoform of prostaglandin G/H synthase. Proc Natl Acad Sci U S A, 91, 11202-11206 (1994).

13. Coussens, L. M. \& Werb, Z. Inflammation and cancer. Nature, 420, 860-867 (2002).

14. Crofford, L. J. COX-1 and COX-2 tissue expression: implications and predictions. J Rheumatol Suppl, 49, 15-19 (1997).

15. Dannhardt, G. \& Kiefer, W. Cyclooxygenase inhibitors-current status and future prospects. Eur J Med Chem, 36, 109-126 (2001).

16. de Gaetano, G., Donati, M. B. \& Cerletti, C. Prevention of thrombosis and vascular inflammation: benefits and limitations of selective or combined COX-1, COX-2 and 5-LOX inhibitors. Trends Pharmacol Sci, 24, 245-252 (2003).

17. Dinarello, C. A. Anti-inflammatory Agents: Present and Future., 140, 935-950 (2010).

18. Traenckner, E. B. M., Pahl, H. L., Henke', T., Wilk, K. N. S. S., Baeuerle, A. \& P Phosphorylation of human IKB-ox on serines 32 and 36 controls IKB-a proteolysis and NF-KB activation in response to diverse stimuli. EMBO, 14, 2876-2883 (1995).

19. Esposito, E. \& Cuzzocrea, S. TNF-alpha as a therapeutic target in inflammatory diseases, ischemiareperfusion injury and trauma. Current medicinal chemistry, 16, 3152-3167 (2009).

20. Fiorucci, S., Meli, R., Bucci, M. \& Cirino, G. Dual inhibitors of cyclooxygenase and 5-lipoxygenase. A new avenue in anti-inflammatory therapy? Biochem Pharmacol, 62, 1433-1438 (2001).

21. Gilmore, T. D. The Rel/NF-kappaB signal transduction pathway: introduction., 18, 6842-6844 (1999).

22. Gilmore, T. D. Introduction to NF-kappaB: players, pathways, perspectives., 25, 6680-6684 (2006).

23. Goodman, J. R. \& Grossman, D. Aspirin and other NSAIDs as chemoprevention agents in melanoma. Cancer Prev Res (Phila), 7, 557-564 (2014).

24. Greene, E. R., Huang, S., Serhan, C. N. \& Panigrahy, D. Regulation of inflammation in cancer by eicosanoids. Prostaglandins Other Lipid Mediat, 96, 27-36 (2011).

25. Grivennikov, S. I., Greten, F. R. \& Karin, M. Immunity, inflammation, and cancer., 140, 883-899 (2010).

26. Hawkey, C. J. COX-1 and COX-2 inhibitors. Best practice \& research. Clinical gastroenterology, 15, 801-820 (2001).

27. Hayden, M. S. \& Ghosh, S. Shared principles in NF-kappaB signaling., 132, 344-362 (2008).

28. Hemler, M. \& Lands, W. E. Purification of the cyclooxygenase that forms prostaglandins. Demonstration of two forms of iron in the holoenzyme. J Biol Chem, 251, 5575-5579 (1976).

29. Hoesel, B. \& Schmid, J. A. The complexity of NF-kappaB signaling in inflammation and cancer. Molecular cancer, 12, 86 (2013).

30. Huang, W. C. \& Hung, M. C. Beyond NF-kappaB activation: nuclear functions of IkappaB kinase alpha. Journal of biomedical science, 20, 3 (2013). 
31. Israel, A. The IKK complex, a central regulator of NF-kappaB activation. Cold Spring Harb Perspect Biol, 2, a000158 (2010).

32. Kalgutkar, A. S. et al. Aspirin-like molecules that covalently inactivate cyclooxygenase-2., 280, 12681270 (1998).

33. Kalgutkar, A. S. et al. Biochemically based design of cyclooxygenase-2 (COX-2) inhibitors: facile conversion of nonsteroidal antiinflammatory drugs to potent and highly selective COX-2 inhibitors. Proc Natl Acad Sci U S A, 97, 925-930 (2000).

34. Kamatham, S. et al. Benzoylsalicylic acid isolated from seed coats of Givotia rottleriformis induces systemic acquired resistance in tobacco and Arabidopsis., 126, 11-22 (2016).

35. Karin, M. 2009. NF-kappaB as a critical link between inflammation and cancer.Cold Spring Harbor perspectives in biology1, a000141.

36. Karin, M. \& Delhase, M. The I kappa B kinase (IKK) and NF-kappa B: key elements of proinflammatory signalling. Seminars in immunology, 12, 85-98 (2000).

37. Ke, J. et al. Role of NF-kappaB in TNF-alpha-induced COX-2 expression in synovial fibroblasts from human TMJ. J Dent Res, 86, 363-367 (2007).

38. Kumar, R. et al. Serum 5-LOX: A progressive protein marker for breast cancer and new approach for therapeutic target (Carcinogenesis, 2016).

39. Kuper, H., Adami, H. O. \& Trichopoulos, D. Infections as a major preventable cause of human cancer. J Intern Med, 248, 171-183 (2000).

40. Lawrence, T. 2009. The nuclear factor NF-kappaB pathway in inflammation.Cold Spring Harbor perspectives in biology 1 , a001651.

41. Lechner, M., Lirk, P. \& Rieder, J. Inducible nitric oxide synthase (iNOS) in tumor biology: the two sides of the same coin. Seminars in cancer biology, 15, 277-289 (2005).

42. Li, J. et al. Baicalein inhibits TNF-alpha-induced NF-kappaB activation and expression of NF-kappaBregulated target gene products. Oncology reports, 36, 2771-2776 (2016).

43. Lim, J. W., Kim, H. \& Kim, K. H. Nuclear factor-kappaB regulates cyclooxygenase-2 expression and cell proliferation in human gastric cancer cells. Lab Invest, 81, 349-360 (2001).

44. Liu, S. et al. Crystal structure of a human IkappaB kinase beta asymmetric dimer. J Biol Chem, 288, 22758-22767 (2013).

45. Oeckinghaus, A. \& Ghosh, S. 2009. The NF-kappaB family of transcription factors and its regulation. Cold Spring Harbor perspectives in biology 1, a000034.

46. Pahl, H. L. Activators and target genes of Rel/NF-kappaB transcription factors., 18, 6853-6866 (1999).

47. Parameswaran, N. \& Patial, S. Tumor necrosis factor-alpha signaling in macrophages. Critical reviews in eukaryotic gene expression, 20, 87-103 (2010).

48. Perkins, N. D. Integrating cell-signalling pathways with NF-kappaB and IKK function. Nat Rev Mol Cell Biol, 8, 49-62 (2007). 
49. Pikarsky, E. et al. NF-kappaB functions as a tumour promoter in inflammation-associated cancer. Nature, 431, 461-466 (2004).

50. Poligone, B. \& Baldwin, A. S. Positive and negative regulation of NF-kappaB by COX-2: roles of different prostaglandins. J Biol Chem, 276, 38658-38664 (2001).

51. Rainsford, K. D., Schweitzer, A. \& Brune, K. Distribution of the acetyl compared with the salicyl moiety of acetylsalicylic acid. Acetylation of macromolecules in organs wherein side-effects are manifest. Biochem Pharmacol, 32, 1301-1308 (1983).

52. Ranjbar, M. M., Assadolahi, V., Yazdani, M., Nikaein, D. \& Rashidieh, B. Virtual Dual inhibition of COX-2 / 5-LOX enzymes based on binding properties of alpha-amyrins, the anti-inflammatory compound as a promising anti-cancer drug. EXCLI J, 15, 238-245 (2016).

53. Rao, P. \& Knaus, E. E. Evolution of nonsteroidal anti-inflammatory drugs (NSAIDs): cyclooxygenase (COX) inhibition and beyond. J Pharm Pharm Sci, 11, 81-110 (2008).

54. Reddanna, P., Whelan, J., Maddipati, K. R. \& Reddy, C. C. Purification of arachidonate 5-lipoxygenase from potato tubers. Methods Enzymol, 187, 268-277 (1990).

55. Reddy, C. M. et al. Selective inhibition of cyclooxygenase-2 by C-phycocyanin, a biliprotein from Spirulina platensis. Biochem Biophys Res Commun, 277, 599-603 (2000).

56. Reddy, D. B. \& Reddanna, P. Chebulagic acid (CA) attenuates LPS-induced inflammation by suppressing NF-kappaB and MAPK activation in RAW 264.7 macrophages. Biochem Biophys Res Commun, 381, 112-117 (2009).

57. Kamatham, S. et al. Benzoylsalicylic acid isolated from seed coats of Givotia rottleriformis induces systemic acquired resistance in tobacco and Arabidopsis (Phytochemistry, 2016).

58. Samuel Kamatham, N. K. \& Gudipalli, P. Isolation and characterization of gallic acid and methylgallate from the seed coats of Givotia rottleriformis Griff. and their anti-proliferative effect on human epidermoid carcinoma A431 cells. Toxicology reports, 2, 520-529 (2015).

59. Schoppmann, S. F. et al. Tumor-associated macrophages express lymphatic endothelial growth factors and are related to peritumoral lymphangiogenesis. Am J Pathol, 161, 947-956 (2002).

60. Seibert, K. \& Masferrer, J. L. Role of inducible cyclooxygenase (COX-2) in inflammation. Receptor, 4, 17-23 (1994).

61. Seibert, K. et al. Pharmacological and biochemical demonstration of the role of cyclooxygenase 2 in inflammation and pain. Proc Natl Acad Sci U S A, 91, 12013-12017 (1994).

62. Shackelford, R. E. et al. Aspirin inhibits tumor necrosis factoralpha gene expression in murine tissue macrophages. Mol Pharmacol, 52, 421-429 (1997).

63. Srivastava, P. et al. Synthesis, anti-inflammatory, analgesic, 5-lipoxygenase (5-LOX) inhibition activities, and molecular docking study of 7-substituted coumarin derivatives. Bioorg Chem, 67, 130138 (2016).

64. Steinhilber, D. 5-Lipoxygenase: a target for antiinflammatory drugs revisited. Curr Med Chem, 6, 7185 (1999). 
65. Sumalatha, M. et al. Isoorientin, a Selective Inhibitor of Cyclooxygenase-2 (COX-2) from the Tubers of Pueraria tuberosa. Natural product communications, 10, 1703-1704 (2015).

66. Surh, Y. J. et al. Molecular mechanisms underlying chemopreventive activities of anti-inflammatory phytochemicals: down-regulation of COX-2 and iNOS through suppression of NF-kappa B activation. Mutat Res, 480-481, 243-268 (2001).

67. Tosato, G. \& Jones, K. D. Interleukin-1 induces interleukin-6 production in peripheral blood monocytes., 75, 1305-1310 (1990).

68. Tu, X. K. et al. 2016. 5-LOX Inhibitor Zileuton Reduces Inflammatory Reaction and Ischemic Brain Damage Through the Activation of PI3K/Akt Signaling Pathway.Neurochem Res.

69. Undas, A., Brummel-Ziedins, K. E. \& Mann, K. G. Antithrombotic properties of aspirin and resistance to aspirin: beyond strictly antiplatelet actions., 109, 2285-2292 (2007).

70. Vallabhapurapu, S. \& Karin, M. Regulation and function of NF-kappaB transcription factors in the immune system. Annu Rev Immunol, 27, 693-733 (2009).

71. Vancurova, I. \& Vancura, A. Regulation and function of nuclear lkappaBalpha in inflammation and cancer. American journal of clinical and experimental immunology, 1, 56-66 (2012).

72. Viatour, P., Merville, M. P., Bours, V. \& Chariot, A. Phosphorylation of NF-kappaB and IkappaB proteins: implications in cancer and inflammation. Trends in biochemical sciences, 30, 43-52 (2005).

73. Vig, M. et al. Inducible nitric oxide synthase in T cells regulates T cell death and immune memory. $J$ Clin Invest, 113, 1734-1742 (2004).

74. Wajant, H., Pfizenmaier, K. \& Scheurich, P. Tumor necrosis factor signaling. Cell death and differentiation, 10, 45-65 (2003).

75. Wei, X. Q. et al. Altered immune responses in mice lacking inducible nitric oxide synthase. Nature, 375, 408-411 (1995).

76. Wentz, A. C., Jones, G. S. \& Sapp, K. C. Investigation of Danazol as a contraceptive agent. Contraception, 13, 619-630 (1976).

77. Willoughby, D. A., Moore, A. R. \& Colville-Nash, P. R. COX-1, COX-2, and COX-3 and the future treatment of chronic inflammatory disease., 355, 646-648 (2000).

78. Xu, G. et al. Crystal structure of inhibitor of kappaB kinase beta. Nature, 472, 325-330 (2011).

79. Yamamoto, Y. \& Gaynor, R. B. Therapeutic potential of inhibition of the NF-kappaB pathway in the treatment of inflammation and cancer. J Clin Invest, 107, 135-142 (2001).

80. Yin, M. J., Yamamoto, Y. \& Gaynor, R. B. The anti-inflammatory agents aspirin and salicylate inhibit the activity of I(kappa)B kinase-beta. Nature, 396, 77-80 (1998).

81. Zandi, E., Rothwarf, D. M., Delhase, M., Hayakawa, M. \& Karin, M. The IkappaB kinase complex (IKK) contains two kinase subunits, IKKalpha and IKKbeta, necessary for IkappaB phosphorylation and NFkappaB activation., 91, 243-252 (1997).

82. Zhang, G. \& Ghosh, S. Molecular mechanisms of NF-kappaB activation induced by bacterial lipopolysaccharide through Toll-like receptors. J Endotoxin Res, 6, 453-457 (2000). 
Figures

\section{Figure 1}<smiles>O=C(O)c1ccccc1O</smiles>

Salicylic acid (2-hydroxy benzoic acid<smiles>CC(=O)Oc1ccccc1C(=O)O</smiles>

Acetyl salicylic acid (2-acetoxy benzoic acid)<smiles>O=C(Oc1ccccc1C(=O)O)c1ccccc1</smiles>

Benzoyl salicylic acid (2-benzoyloxy benzoic acid)

\section{Figure 1}

Representative chemical composition of (a) Salicylic acid (SA), (b) Acetylsalicylic acid (ASA) and (c) Benzoyl salicylic acid (BzSA). 
Figure 2

a

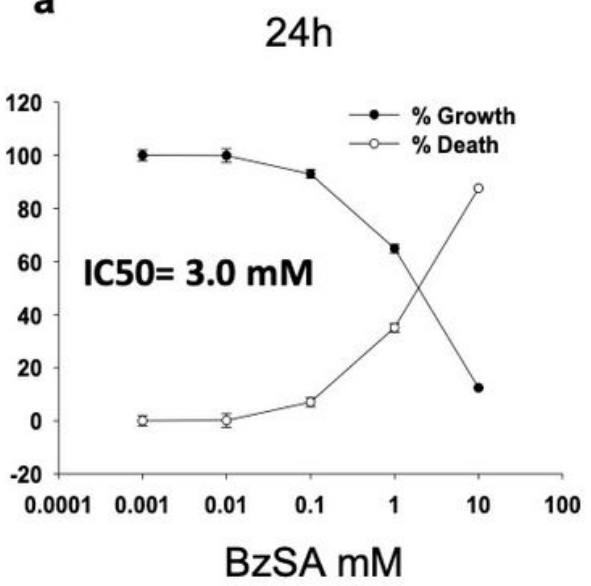

d

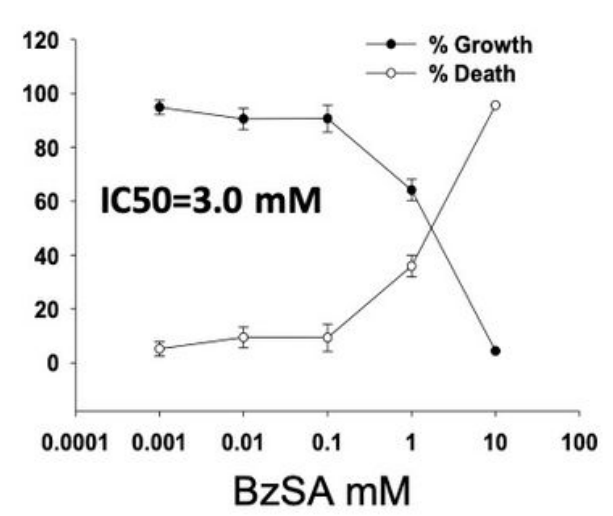

b

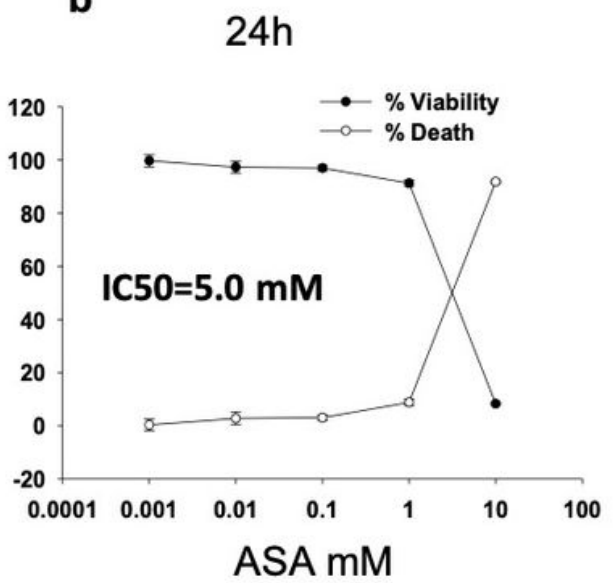

e $\quad 48 \mathrm{~h}$

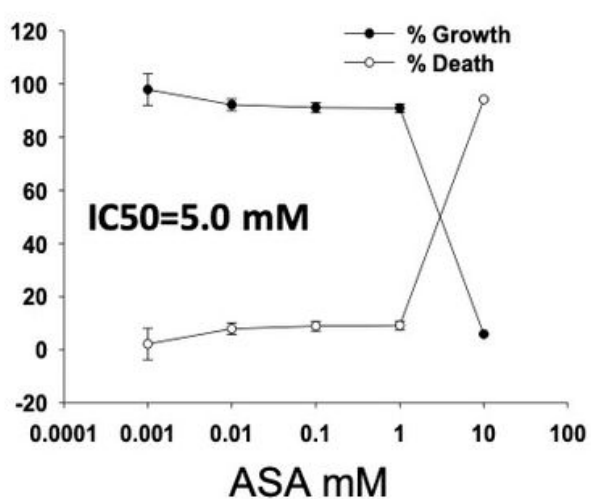

c

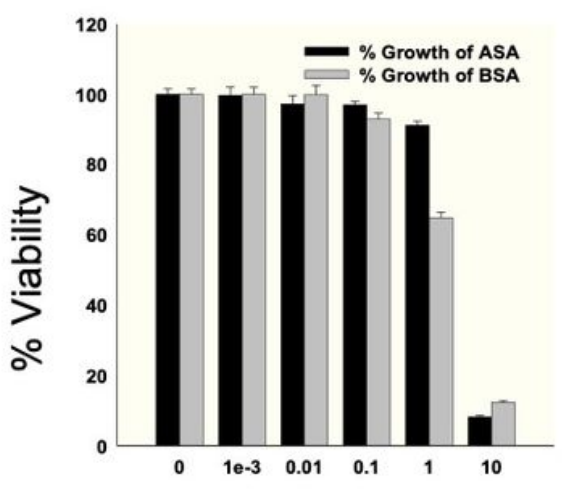

BzSA and ASA conc.

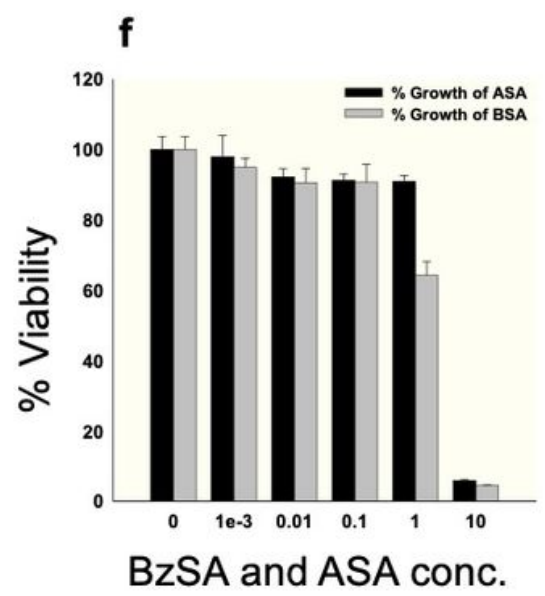

\section{Figure 2}

Determination of cytotoxic effect of BzSA and ASA in RAW 264.7 cells by MTT assay. RAW 264.7 cells were cultured and pre-treated with increasing concentrations of BzSA and ASA $(0.001,0.01,0.1,1,10$, $100 \mathrm{mM}$ ) and the cytotoxicity of BzSA and ASA were measured as cell death after $24 \mathrm{~h}$ and $48 \mathrm{~h}$. (a) showing the cytotoxic effect of BzSA with an IC50 value of $3.0 \mathrm{mM}$ after 24h of BzSA pre-treatment. (b) Showing the cytotoxic effect of ASA with an IC50 value of $5.0 \mathrm{mM}$ after 24h of ASA pre-treatment. (c) Showing the percentage of (\%) cell viability in BzSA and ASA pre-treated RAW 264.7 cells after 24h pretreatment. (d\&e) Showing the IC50 value of BzSA and ASA pre-treated RAW 264.7 cells after 48h. (f) Showing the percentage of cell viability in BzSA and ASA pre-treated cells after $48 \mathrm{~h}$ pre-treatment. Values representing here are average of 3 independent experiments. 
Figure 3
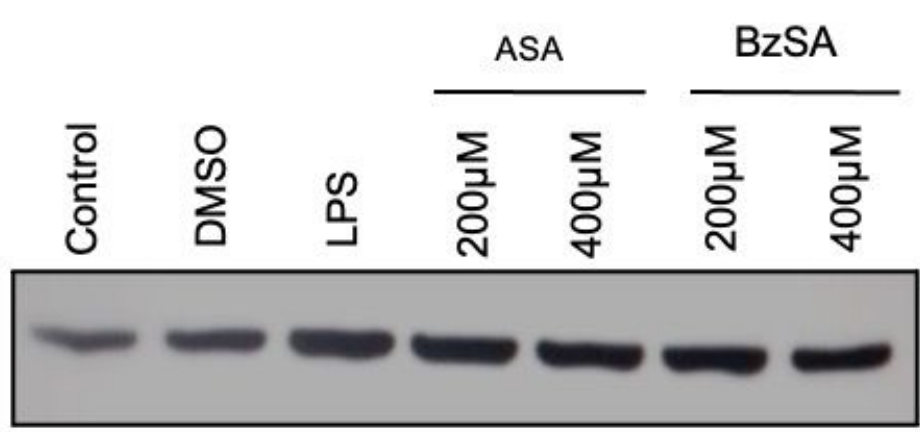

$\operatorname{cox}-1$

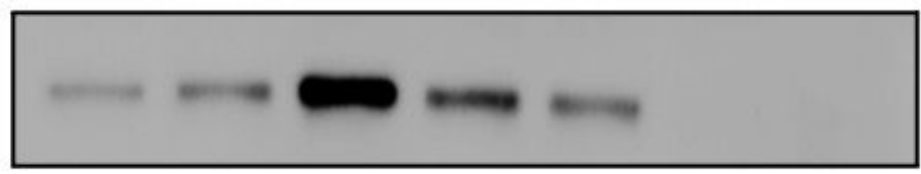

$\operatorname{cox}-2$

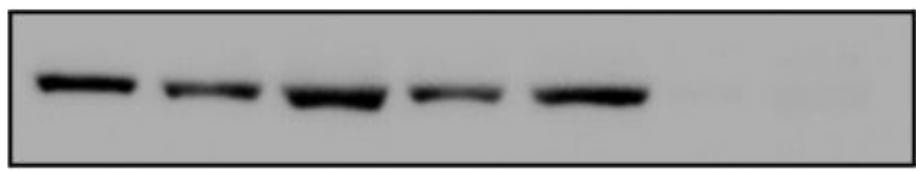

5-LOX

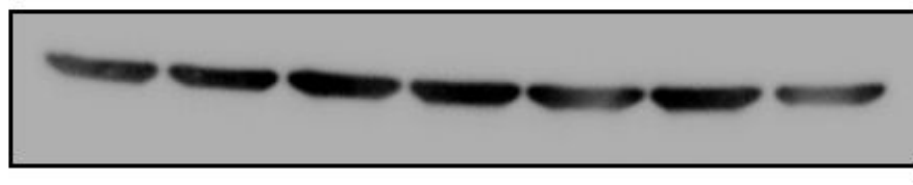

$\beta$-Actin

LPS

DMSO

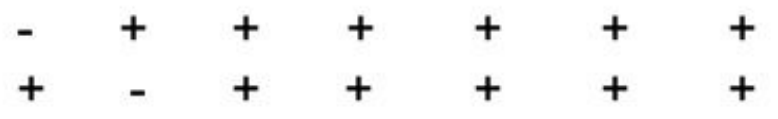

\section{Figure 3}

Effect of BzSA on COX-1, COX-2 and 5-LOX expression in RAW 264.7 cells. Raw 264.7 cells were pretreated with BzSA in a dose-dependent manner for $24 \mathrm{~h}$ followed by stimulated with LPS. The whole cell protein lysate was prepared and performed western blotting analysis. Blots showing the effect of BzSA and ASA on LPS stimulated COX-1, COX-2 and 5-LOX expression in BzSA pre-treated cells as compared to ASA. DMSO $0.01 \% / \mathrm{ml}$ and $0.25 \mu \mathrm{g} / \mathrm{ml}$ LPS treated RAW 264.7 cells was used as controls. Beta-actin served as a loading control. 


\section{RAW264.7 cells}

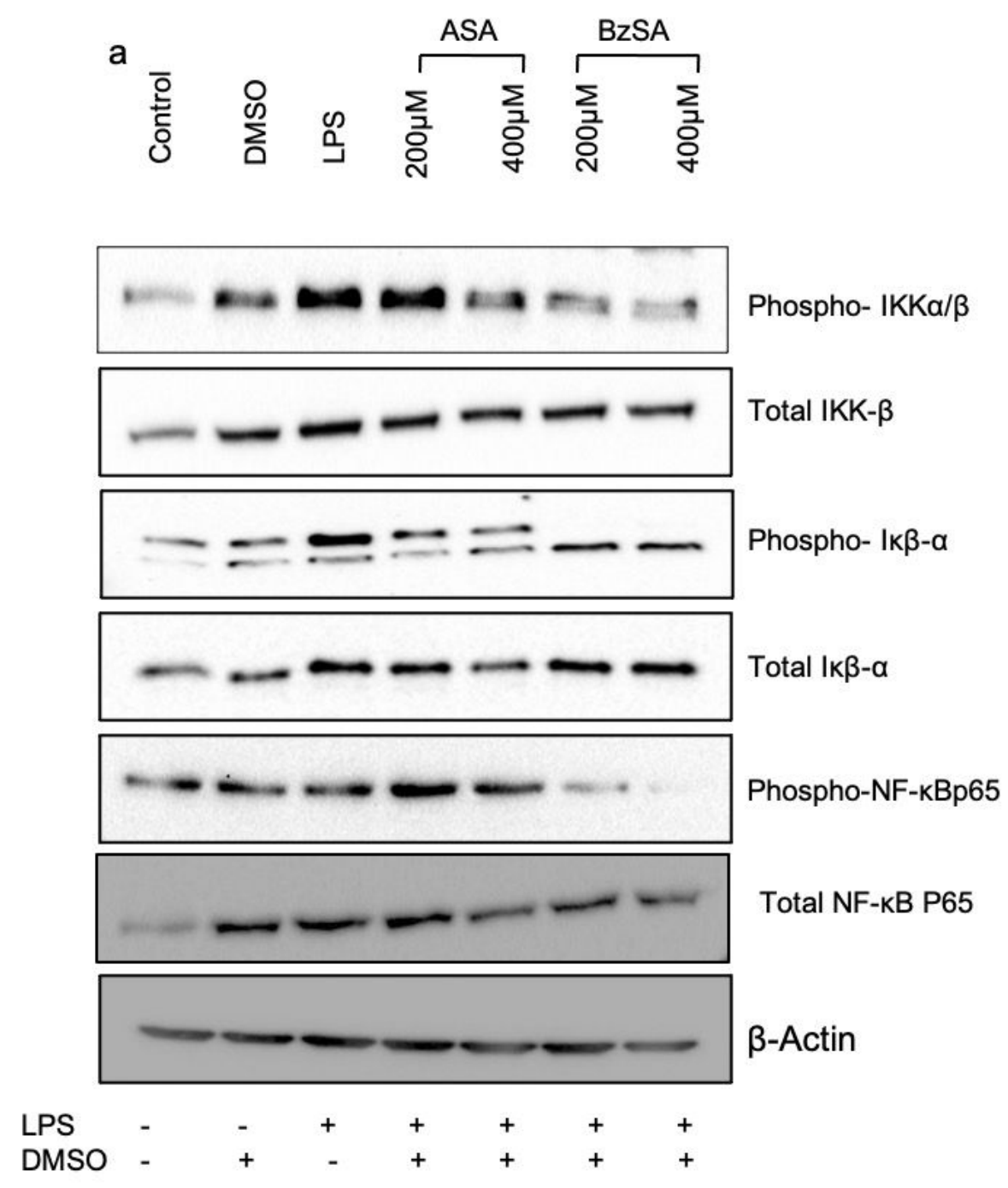

Figure 4

Effect of BzSA on IKK- complex (IKK-a / IKK- $\beta$ ), IKB- $a$ and NF-KB in RAW 264.7 cells. Raw 264.7 cells were cultured and pre-treated with BzSA and ASA for $24 \mathrm{~h}$ and then the cells were stimulated with $0.25 \mu \mathrm{g} / \mathrm{mL}$ LPS. Then the whole cell protein lysate of treated and untreated cells were prepared and performed

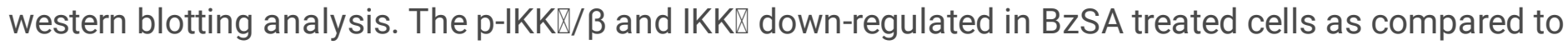
ASA. plкB- $\alpha$ and total-IкB down -regulated in BzSA treated cells as compared to ASA. NF-kBp65 downregulated in BzSA pre-treated cells upon LPS stimulation as compared to ASA. DMSO, LPS stimulated RAW 264.7 cells was used as control. Beta-actin served as a loading control. 
Figure 5

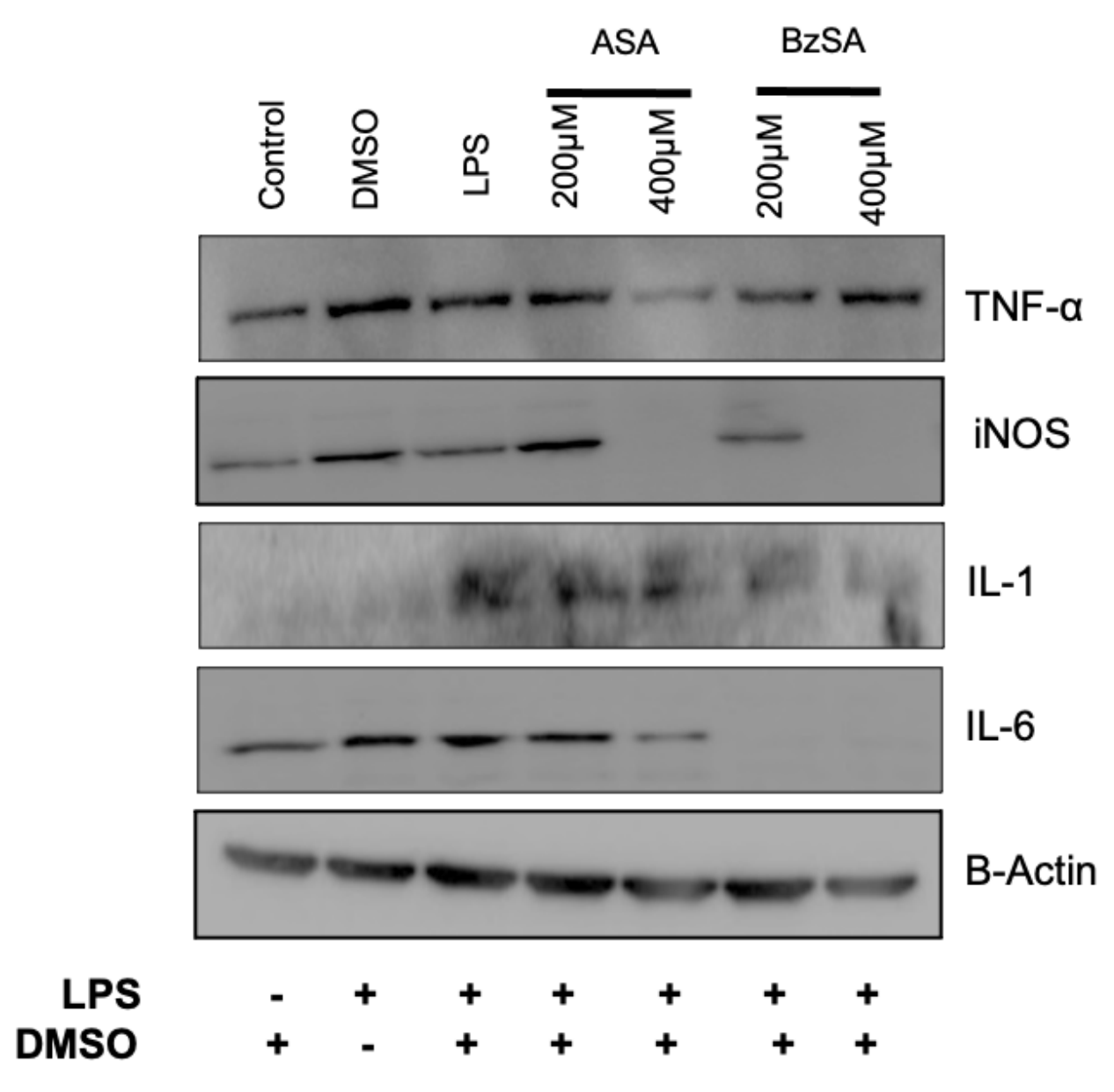

Figure 5

Effect of BzSA on TNF-a, iNOS, IL-1 $\beta$ and IL-6 expression in RAW 264.7 cells. Raw 264.7 cells pre-treated with BzSA and ASA for $24 \mathrm{~h}$ followed by stimulated with LPS. The whole cell protein lysate was prepared and performed western blotting analysis. Down-regulation of TNF-a, iNOS, IL-1 $\beta$ and IL- 6 in BzSA pretreated cells upon stimulation with LPS as compared to ASA. DMSO $0.01 \% / \mathrm{ml}$ and $0.25 \mu \mathrm{g} / \mathrm{ml}$ LPS treated RAW264.7 cells was used as controls. Beta-actin was served as a loading control. 


\section{Figure 6}

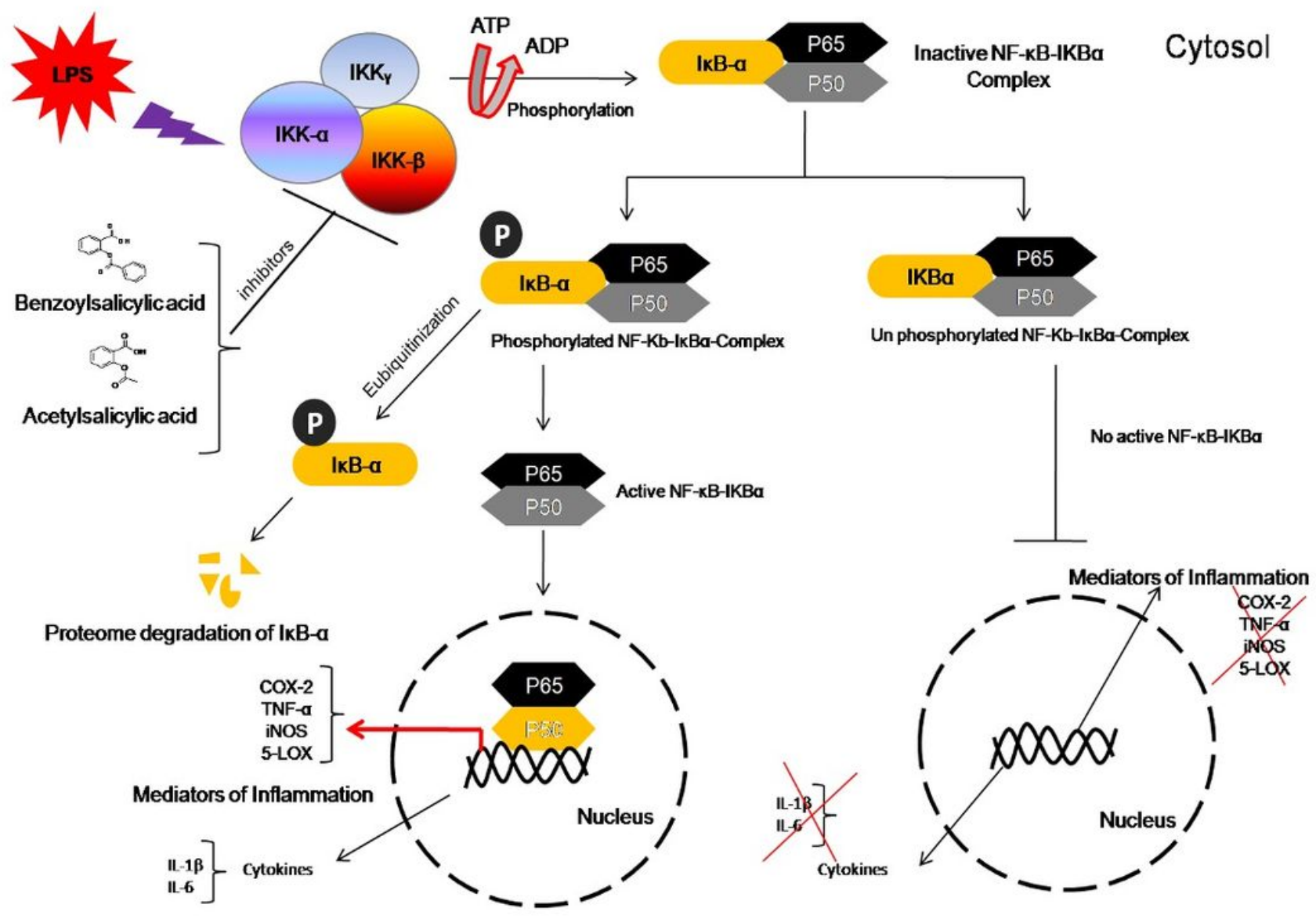

Figure 6

Proposed mechanism of NF-KB pathway inhibition in BzSA pre-treated RAW 264.7 cells upon LPS stimulation. 